\title{
COMMENTARY
}

\section{Creating Snapshots of Our Education Contributions}

\author{
Simon P. Albon, PhD, ${ }^{a}$ Janet H. Cooley, PharmD, ${ }^{b}$ Kristin K. Janke, $\mathrm{PhD}^{\mathrm{c}}$ \\ ${ }^{a}$ University of British Columbia, Vancouver, British Columbia, Canada \\ ${ }^{\mathrm{b}}$ University of Arizona, College of Pharmacy, Tucson, Arizona \\ ${ }^{\mathrm{c}}$ University of Minnesota, College of Pharmacy, Minneapolis, Minnesota
}

Corresponding Author: Janet H. Cooley, University of Arizona, College of Pharmacy, 1295 N. Martin Ave, PO Box 210202, Tucson, AZ 85721. Tel: 520-626-5095. Email: cooley@ pharmacy.arizona.edu

Submitted March 4, 2021; accepted May 17, 2021; ePublished May 2021

Education contributions are significant, but often challenging to document and describe. In addition, contributions may go unrecognized or rewarded unless the work results in publication or presentation. Drawing on a metaphor of the importance of the fisher's photo to capture memories of successful fishing trips, this commentary examines methods to identify and organize contributions. Frameworks and a visual tool are presented to assist pharmacy educators in thinking systematically about the full breadth of education contributions. Using the frameworks and visualization tool, a more complete picture of education contributions develops, allowing educators to create visual snapshots of their work for others to see and appreciate.

Keywords: teaching, recognition, scholarship of teaching

\section{The Need to Showcase Education Contributions}

After landing a particularly noteworthy catch, the excited fisher might reach for a camera to document the occasion. The photo is evidence of hard work, sustained effort, and pride. Sharing the photo with others often opens a spirited discussion about the challenges and successes of the process. The viewers may even be inspired to trade experiences and exchange knowledge. Like the fisher with snapshots of their accomplishments, pharmacy educators need to document and showcase their teaching experiences for others to see and appreciate.

Stakeholders, such as Deans and department heads, want to know about faculty activities. However, pharmacy educators may struggle with mechanisms for reporting their work in annual reviews, as well as reappointment, promotion, and tenure processes. While efforts have been made to recognize teaching excellence in pharmacy, it remains challenging to identify, describe, and document the breadth of education-related activities. ${ }^{1,2,3}$ Logging classroom hours, numbers of students precepted, and articles published are insufficient for capturing the full scope of education-related contributions. To make education more "visible and valued," medical educators have suggested five categories of educational activity: teaching, curriculum development, advising and mentoring, education leadership, and administration and learner assessment. ${ }^{4,5}$ Amongst the supporting evidence options for these education contributions, activities that are easy to count and list predominate, and publication continues to be privileged and highly valued. ${ }^{6,7,8}$ Given the wide range of activities that support education, it is critical that faculty be provided the language, tools, and frameworks to consider the full scope of their educational activities and to document both their quantity and quality. ${ }^{4,5,8}$ The aim of this paper is to expand the discussion about education-related contributions in academic pharmacy to aid in them being more visible and valued. More specifically, it discusses: 1) broadening our thinking regarding education contributions, 2) frameworks to help identify, organize, and showcase contributions, and 3) a specific tool for succinctly describing, documenting, presenting visually, and reflecting upon contributions more fully.

\section{Recognizing the Full Breadth of Contributions}

As part of annual reporting processes, most pharmacy educators have spent time brainstorming and asking themselves, "What education-related activities did I complete this year?" While some activities are obvious and required on the Curriculum Vitae (CV), such as presentations, funding received, and committee involvement, there are likely many other less obvious activities deserving of documentation. Figure 1, developed through brainstorming by the authors and refined through feedback from multiple groups of faculty, presents a sampling of many different education-related activities. On this Figure, the typical CV items represent only a few of the more than 40 activities that could be shared with stakeholders. Clearly, to acknowledge the full scope of an educator's work, careful consideration is needed. 
Figure 1 is not meant to be comprehensive. Examples can and should be added. It is also not meant as a checklist or to suggest that each educator have every one of these activities represented in their work. Figure 1 simply seeks to broaden our perspective on education contributions, so that the academy can better recognize contributions and illuminate those that may not be as visible and valued. In reality, educators do not have just one or two "prize fish" to showcase. Each semester results in a bounty of catch (contributions) that require a collective, thoughtful display.

\section{Thinking Systematically about Education Contributions}

Using frameworks may be helpful for thinking systematically about the full scope of education-related activities. As a starting point, most pharmacy educators are familiar with sorting and organizing their work as research, teaching, and service. While this time-tested framework may be familiar, using it may not prompt educators to include the broader array of education contributions.

For a more comprehensive view, the framework described by Simpson and colleagues may be useful. ${ }^{4,5}$ This alternate approach specifically prompts activities in curriculum development (eg, creation of new programs or quality improvement procedures), advising and mentoring (eg, coaching in a teaching certificate program for residents), education leadership and administration (eg, becoming the faculty point-person for co-curriculum or interprofessional education), and learner assessment (eg, the creation of a new student observation checklist for a simulation). ${ }^{4,5} \mathrm{~A}$ fisher provides a coherent story that articulates and emphasizes their effort, skill and dedication. Likewise, educators must not only identify, but also organize their education-related contributions, in order to effectively scaffold the communication about their work. Pushing the boundaries of the traditional CV categories may be necessary to adequately document and showcase this work.

Once educational contributions are identified and organized, faculty can expect that they will be scrutinized by stakeholders. While this may include the quantity of the contributions, moving beyond lists and describing the education activities and role responsibilities is encouraged. In addition, supporting evidence of the quality of these contributions should be collated. Learning evidence, student ratings of teaching, and peer evaluations are just some of the ways to communicate achievements to others. ${ }^{2,4,5}$ Simpson and colleagues also suggest that framing contributions locally, regionally, nationally and internationally can provide powerful messaging about academic engagement. ${ }^{4,5}$ As schools seek to make education more visible and valued, strong and persistent advocacy is needed to shift institutional policies and practices toward stronger documentation, evaluation and recognition. ${ }^{9}$

A framework can also aid in thinking proactively about the future and negotiating teaching responsibilities over time. Ideally, an educator's contributions meet tangible student and curricular needs. However, in an ideal situation, there is also a match between those needs and the contributions that best align with the educator's teaching talents, expertise, and interests. Hitting this "sweet spot" between institutional and individual faculty needs can be tricky, especially when there are other educators to consider. In preparation for these conversations, educators can use the frameworks above and the tool described below to see the full picture of their current contributions, as well as those they could or should make.

\section{Creating a Visual Snapshot of Education Contributions}

Following discussions within the University of British Columbia's Centre for Teaching, Learning and Technology and honed through extensive campus-wide stakeholder workshops, the Educational Leadership Mapping or "ELM Tool" was developed. ${ }^{10}$ Figure 2 provides the Tool and an example of its use. It provides a robust framework for critically examining education-related activities in ways that can be documented and clearly described in annual reports and for career advancement decisions. The ELM Tool is a two-dimensional representation of the intellectual work of teaching. The "dimensions of teaching" are represented by a continuum of activities ranging from delivering teaching/learning activities to dissemination. Implied is a kind of directionality and a sense of professional growth where teaching excellence, scholarly teaching, and the Scholarship of Teaching and Learning are important considerations for educators and emerging educational scholars, including pharmacy academics. ${ }^{2,11}$ Traditional teaching documentation may tend to focus at the "practitioner" level, emphasizing the work that the teacher is doing, particularly instructional delivery. However, in "forms of enactment," additional activities are documented, including those that enable instruction as "manager" (eg, planning, training of teaching assistants, coordinating the teaching team), as well as activities that motivate and influence others at the "leader" level (eg, local colleagues, disciplinary peers, Faculty policies). ${ }^{12}$ In practice, the ELM Tool allows educators to examine, tease apart and map the different aspects of their teaching and learning work in terms of roles, activities, and influence. Importantly, no aspect of education-related work is privileged and instead, its full breadth is seen as highly interwoven and synergistic. The ELM Tool: 1) helps identify the products of educationrelated work, creating tangible evidence for documenting and sharing with others, and 2) provides a powerful visual 
validation of the efforts educators are undertaking to improve the quality of teaching practices and programs, as well as their growth as educators and educational scholars.

To illustrate teaching-related contributions for a course, one author mapped activities related to his medicinal chemistry teaching (ie, a 10-week year one module). The lower left-hand corner (ie, "delivery" and "doing") represents the face-to-face time spent with students in lecture and during tutorials, called Integration Activities (IA). The next entry documents the activities related to designing and enabling the education, which can represent considerable time and investment. Tangible evidence of this work is represented as outputs or educational artifacts (eg, syllabi, problems sets, and exams) that can be shared with others and/or listed, described, and documented in CVs and teaching dossiers, as applicable. The last entry documents the influence of professional growth as a scholar on the quality of the medicinal chemistry curriculum and pedagogical practices within the school and nationally in the form of a new medicinal chemistry special interest group (SIG) for teachers. ${ }^{13}$ This entry may have been missed without the focused thought prompted by the influencing row of the Tool.

As described above, the ELM Tool aids the user in describing and documenting their work more fully. Although teaching portfolios have also been used to describe and document contributions and certainly have value, they can require significant time to assemble and to read. ${ }^{14}$ An advantage of the ELM Tool is that versions can be drafted relatively quickly, with entries added or updated as new insights occur. In addition, the succinct visual created can be easily shared in documentation (eg, annual reviews, dossiers, portfolios). Regarding the full scope of teaching activities, the Tool can be applied in different teaching contexts (eg, classroom, experiential, other subject areas) or with different audiences (eg, professional students, residents, graduate students) resulting in multiple snapshots of the work of teaching, and when compiled over semesters and years, can capture the shifts in teaching responsibilities and the full scope of contributions to institutional educational mandates for promotion or award dossiers.

The ELM Tool also supports teacher reflection. Once a draft is made, the resultant "white spaces" can be examined. Figure 2, for example, exposes significant gaps on either side of the mapped activities, prompting questions, such as "Are there ways that medicinal chemistry is being delivered that might be influencing others?" or "Are there aspects of wisdom gained as a teaching practitioner that should be disseminated and made public?" After identifying an important gap in the influence-disseminate area (upper right), the Tool's user responded by initiating focused scholarly inquiry aimed at exploring the relevance of learning medicinal chemistry in the Doctor of Pharmacy curriculum. In addition, reflection identified opportunities to disseminate the learning-centered curriculum design and pedagogical practices at local and national conferences. As emphasized previously, iterations of the Tool can be compiled and superimposed, like transparencies, to see strengths and identify gaps across the entirety of education contributions.

While the goal is not to fill the entire figure, the ELM Tool can be used to help determine possible future actions within the context of the educator's role, interests, and expectations. Another author plotted each major activity or goal for the next year onto the ELM Tool. In doing this, the "Practitioner" row filled quickly with courses requiring instruction (delivery) and coordination (design). Also, with an administrative role, there were activities in the "Manager" (enable) row. However, there were gaps in the "Leader" row, as well as gaps in the columns for "Scholarly reflection, professional growth" and "Scholarship and public dissemination". Seeing activities mapped created a visual representation of currently planned time and effort and highlighted the need for additional conversations to initiate work in missing areas now and/or in the future. Using the ELM Tool in this way, with specific stakeholders or audiences in mind, provided a helpful way to organize current education contributions, prepare for important conversations, and plan for the future. On its own, the fisher's story may be compelling, but a visual can help to focus the listener's attention and aid conversations about the fisher's actions, abilities, and plans. Stakeholders have indicated that the ELM Tool has focused their attention through a common language for discussing teaching and learning work, purposeful identification and listing of the products of teaching work, proactive thinking about "gaps", and more sophisticated discussions about the intellectual work of teaching overall. While ELM map(s) can become complex and messy, the visual has positively prompted stronger documentation of the full scope of educator's educational activities, influence, and growth.

\section{Making Education Visible and Valued}

If our fisher came home without a picture, the response to their expedition would be different. Without the picture, the listener might find it more difficult to appreciate the effort or to engage in conversation. In addition, if our fisher came home without a story - just a long list of facts - they would also face a different reception. Likewise, educators should fully document and "hold up" their contributions for others to see. A framework, such as the ELM Tool, can prompt reflection and guide organization for more effective presentation of the work. In addition, examining our collective catch can aid in garnering support and identifying the next trip (ie, teaching-related investment) we can/should 
make. In our quest to make education contributions visible and valued, pharmacy educators must continue to work to find methods to document and share teaching activities and accomplishments.

\section{ACKNOWLEDGEMENTS}

The ELM tool is available through a Creative Commons License (Attribution-Non-Commercial-ShareAlike, ie CC BY-NC-SA). Conceptualization of the ELM Tool represented in Figure 2 and its development into a visual is credited to Drs. Simon Bates and Isabeau Iqbal.

\section{REFERENCES}

1. Hammer D, Piascik P, Medina M, et al. Recognition of teaching excellence. Am J Pharm Educ. 2010;74(9):164. doi:10.5688/aj7409164

2. Piascik P, Bouldin A, Schwarz L, et al. Rewarding excellence in pharmacy teaching. Curr Pharm Teach Learn. 2011;3(4):249-254. doi.org/10.1016/j.cpt1.2011.07.006

3. Smith KM, Crookes PA, Else F, Crookes E. Scholarship reconsidered: Implications for reward and recognition of academic staff in schools of nursing and beyond. J Nurs Manag. 2012;20(2):144-151. doi:10.1111/j.13652834.2011.01374.x

4. Simpson D, Fincher RM, Hafler JP, et al. Advancing educators and education by defining the components and evidence associated with educational scholarship. Med Educ. 2007 Oct;41(10):1002-9. doi: 10.1111/j.13652923.2007.02844.x.

5. Simpson D, Fincher RM, Hafler JP, et al. Advancing Educators and Education: Defining the Components and Evidence of Educational Scholarship; Summary Report and Findings from the AAMC Group on Educational Affairs Consensus Conference on Educational Scholarship. Association of American Medical Colleges. 2007.

6. Medina M, Hammer D, Rose R, et al. Demonstrating excellence in pharmacy teaching through scholarship. Curr Pharm Teach Learn. 2011; 3(4): 255-259. https://doi.org/10.1016/j.cptl.2011.07.008

7. Behar-Horenstein LS, Beck DE, Su Y. Perceptions of pharmacy faculty need for development in educational research. Curr Pharm Teach Learn. 2018; 10(1): 34-40. https://doi.org/10.1016/j.cptl.2017.09.019

8. Medina MS, Draugalis JR. Exploring Impact Metrics Beyond Indices and Citations for SOTL and Applied Educational Research. Am J Pharm Educ. 2019;83(3):7211. doi:10.5688/ajpe7211

9. Irby DM, O'Sullivan PS. Developing and rewarding teachers as educators and scholars: remarkable progress and daunting challenges. Med Educ. 2018;52(1):58-67. doi:10.1111/medu.13379

10. University of British Columbia, Centre for Teaching, Learning and Technology. Educational Leadership. https://ctlt.ubc.ca/programs/all-our-programs/teaching-and-educational-leadership/. Accessed May 14, 2021.

11. Medina MS, Bouldin AS, Gonyeau M, et al. Report of the 2011-2012 Academic Affairs Standing Committee: the evolving role of scholarly teaching in teaching excellence for current and future faculty. Am J Pharm Educ. 2012;76(6):S5. doi:10.5688/ajpe766S5

12. Marshall SJ, Orrell J, Cameron A, Bosanquet A, Thomas S. Leading and managing learning and teaching in higher education. High Educ Res Dev. 2011; 30(2): 87-103. https://doi.org/10.1080/07294360.2010.512631

13. Association of Faculties of Pharmacy of Canada. Association of Faculties of Pharmacy Special Interest Groups. https://afpc.info/content/afpc-special-interest-groups-0. Accessed May 14, 2021.

14. Simpson D, Hafler J, Brown D, Wilkerson L. Documentation systems for educators seeking academic promotion in U.S. medical schools. Acad Med. 2004; 79(8): 783-90. doi: 10.1097/00001888-200408000-00014 
Figure 1: A brief brainstorm of education-related activities and contributions.

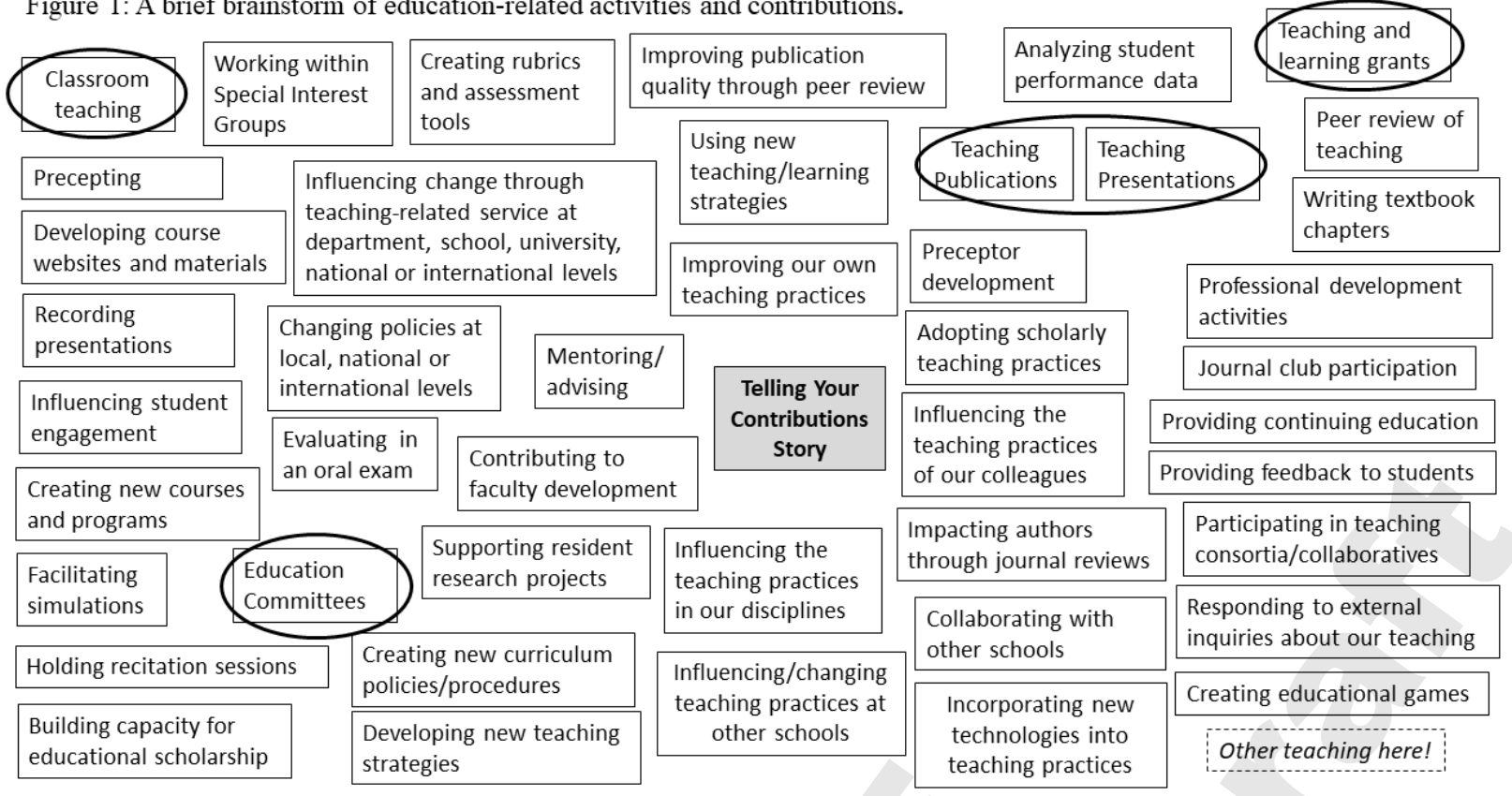

Figure 1 Legend:

Circles represent teaching contributions typically found on the CV.

Figure 2. The Educational Leadership Mapping Tool and Its Application to an Example of Medicinal Chemistry Teaching

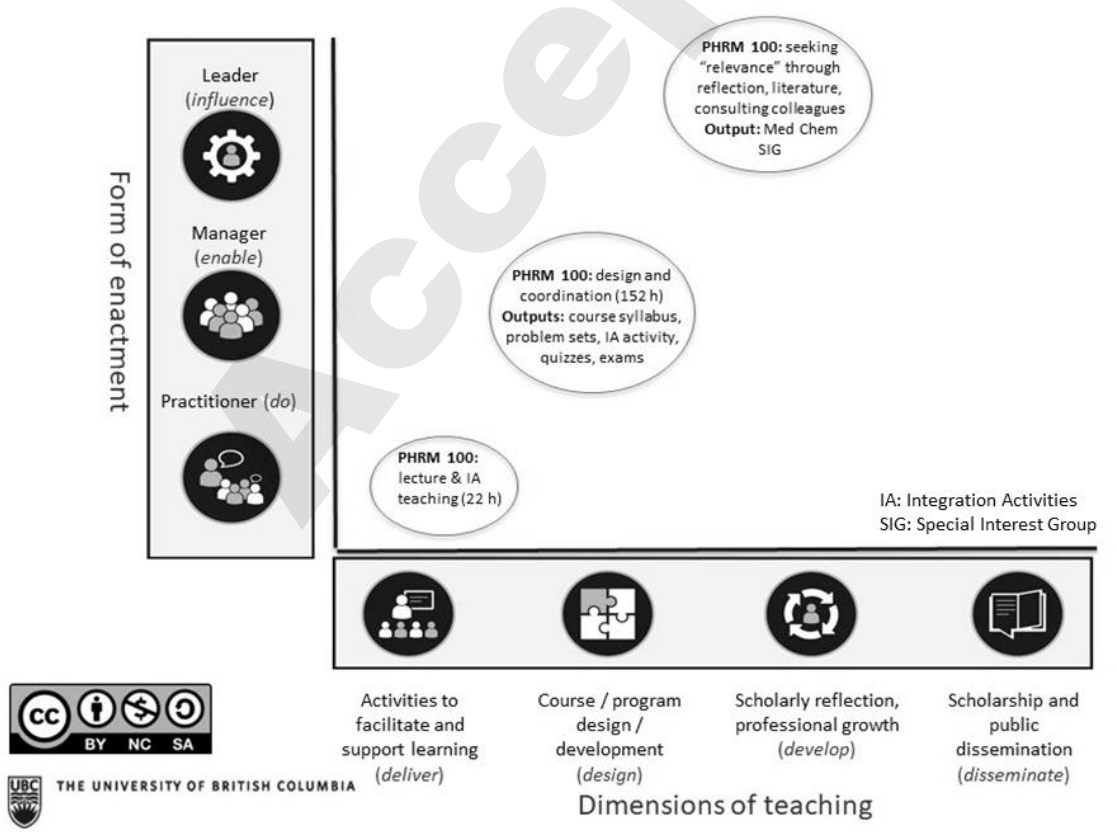

